\title{
Clinical utility of late-night and post-overnight dexamethasone suppression salivary cortisone for the investigation of Cushing's syndrome
}

\author{
CM Ng *, TK Lam, YC Au Yeung, CH Choi, YP lu, CC Shek, SC Tiu
}

\section{A B S T R A C T}

Introduction: There is a pressing need to identify diagnostic testing for Cushing's syndrome that can be achieved with ease and at low cost. This study aimed to explore the usefulness of late-night and postovernight 1-mg dexamethasone suppression salivary cortisone, as measured by liquid chromatographytandem mass spectrometry, for investigation of hypercortisolism.

Methods: Salivary cortisone data of subjects were investigated according to a pre-specified protocol Subjects were classified as having 'hypercortisolism' or 'eucortisolism' on the basis of histological or biochemical criteria. Receiver operating characteristic curves were drawn to identify the cut-off values and study their performance characteristics. We measured 24-hour urinary free cortisol; late-night salivary cortisol and cortisone; and post-overnight 1-mg dexamethasone suppression serum cortisol, and salivary cortisol and cortisone. Saliva and urine samples were assayed by liquid chromatography-tandem mass spectrometry.

Results: In this study, 21 subjects were classified as having hypercortisolism and 78 as having eucortisolism. A late-night salivary cortisone cut-off of $13.50 \mathrm{nmol} / \mathrm{L}$ had a sensitivity of $94.7 \%$ and a specificity of $87.2 \%$. After taking 1-mg dexamethasone the night

This article was published on 13 Oct 2017 at www.hkmj.org. before, a salivary cortisol cut-off of $0.85 \mathrm{nmol} / \mathrm{L}$ had a sensitivity of $76.2 \%$ and a specificity of $96.2 \%$; a salivary cortisone cut-off of $7.45 \mathrm{nmol} / \mathrm{L}$ had a sensitivity of $85.7 \%$ and a specificity of $94.9 \%$, while a salivary cortisone cut-off of $3.25 \mathrm{nmol} / \mathrm{L}$ had a sensitivity of $95.2 \%$ and a specificity of $79.5 \%$. Many salivary cortisol samples were below the detection limit of liquid chromatography-tandem mass spectrometry. In comparison with salivary cortisol, salivary cortisone had a better correlation with total serum cortisol and better diagnostic performance following dexamethasone suppression.

Conclusions: Both late-night and post-overnight dexamethasone suppression salivary cortisone levels are of diagnostic value in the investigation of hypercortisolism.

\section{Hong Kong Med J 2017;23:570-8}

DOI: $10.12809 / \mathrm{hkmj} 176240$

\footnotetext{
${ }^{1} \mathrm{CM} \mathrm{Ng}$ *, FRCP (Edin), FHKAM (Medicine)

TK Lam, MB, BS, MRCP

${ }^{1}$ YC Au Yeung, MRCP, FHKAM (Medicine)

${ }^{1} \mathrm{CH}$ Choi, FRCP (Edin), FHKAM (Medicine)

${ }^{2}$ YP lu, BSc, MSc

${ }^{2}$ CC Shek, MB, BS, FHKAM (Pathology)

${ }^{1}$ SC Tiu, MD, FHKAM (Medicine)
}

${ }^{1}$ Department of Medicine

2 Department of Pathology

Queen Elizabeth Hospital, Jordan, Hong Kong

* Corresponding author: ngcm2@ha.org.hk

New knowledge added by this study

- Compared with salivary cortisol, salivary cortisone has better diagnostic performance after dexamethasone suppression.

- Both late-night and post-overnight dexamethasone suppression salivary cortisone levels are of diagnostic value in the investigation of hypercortisolism.

Implications for clinical practice or policy

- Using the cut-off value generated from this study, late-night and post-overnight dexamethasone suppression salivary cortisone, measured by liquid chromatography-tandem mass spectrometry, can be added to the panel of diagnostic tests for hypercortisolism.

\section{Introduction}

The diagnosis of Cushing's syndrome, especially when hypersecretion is mild, is plagued by uncertainties. Most clinical features-such as diabetes mellitus, hypertension, obesity, hyperlipidaemia, osteoporosis, or depression-are non-specific and highly prevalent in the general population. More specific features such as myopathy or easy bruising may be absent even in subjects with florid biochemical hypercortisolism. In addition, no single test can diagnose Cushing's syndrome with $100 \%$ sensitivity and specificity. ${ }^{1}$ It is a common phenomenon that tests for hypercortisolism-for examples, 24-hour urinary free cortisol (UFC), late- 
night salivary cortisol $\left(\mathrm{SalF}_{\mathrm{LN}}\right)$ or serum cortisol level after 1-mg overnight dexamethasone suppression test $\left(\mathrm{SerF}_{\mathrm{Dex}}\right)$-often produce discordant results. Each test has its own caveats, affected by the level of binding proteins, completeness of urine collection, and absorption and metabolism of dexamethasone. In recent years, increased awareness of the metabolic and cardiovascular consequences of Cushing's syndrome $^{2}$ has led to a pressing need to identify tests that are easy to perform and can provide useful information at a low cost.

Collection of saliva samples is non-invasive and stress-free. ${ }^{3,4}$ Salivary cortisol is not affected by the levels of binding proteins so it provides a reliable indication of the biologically active free serum cortisol level. ${ }^{5}$ Significant advances have been made with the use of salivary cortisol in the investigation of hypercortisolism..$^{3,6-9}$ The availability of liquid chromatography-tandem mass spectrometry (LC-MS/MS) also enables the measurement of other glucocorticoid analytes. Among these and of particular interest is cortisone that is present in the saliva at a higher concentration-the salivary cortisone-to-cortisol ratio is up to $6-8: 1^{10-12}-$ due to conversion of cortisol to cortisone by the 11 beta-hydroxysteroid dehydrogenase 2 (11 $\beta$ HSD2) enzyme in the salivary glands. ${ }^{13}$ This higher concentration makes it more detectable than salivary cortisol. ${ }^{10}$ Salivary cortisone has been shown by some investigators to have a better and more linear relationship with serum total cortisol $^{14}$ and serum free cortisol ${ }^{10}$ than salivary cortisol.

In this study, we reviewed the late-night salivary cortisone $\left(\mathrm{SalE}_{\mathrm{LN}}\right)$ and post-overnight dexamethasone suppression salivary cortisone $\left(\mathrm{SalE}_{\mathrm{Dex}}\right)$ values of subjects being investigated for hypercortisolism in our centre, in an attempt to define cut-off values with reasonable sensitivity and specificity.

\section{Methods}

\section{Subjects}

All subjects referred to the Endocrine Unit of Queen Elizabeth Hospital in Hong Kong for suspected endogenous hypercortisolism were evaluated according to a pre-specified protocol. Written informed consent was obtained from all subjects. The results of subjects investigated during May 2013 (when salivary measurement by LC-MS/MS became available) to September 2016 were reviewed. This study was approved by the Hospital Ethics Committee. No patient was receiving medical treatment for Cushing's syndrome at the time of assessment. Subjects who were taking medication (such as rifampicin, phenytoin, phenobarbital, and alcohol) that might interfere with dexamethasone metabolism, or were night or shift workers, were excluded.

\section{使用深夜唾液皮質素和隔夜dexamethasone抑制 唾液皮質素偵測Cushing綜合徵的臨床應用 \\ 伍超明、林子敬、歐陽亦璋、蔡祥熙、姚恩萍、 \\ 石志忠、張秀祥}

引言：使用一個簡易和低成本的診斷測試Cushing綜合徵很重要。本 研究旨在探討經相色譜一串聯質譜聯用 ( LC-MS / MS ) 來量度的深 夜唾液皮質素和隔夜 $1 \mathrm{mg}$ dexamethasone抑制唾液皮質素偵測皮質醇 增多症的效用

方法: 根據預先計劃好的方案研究病人的唾液皮質素數據。按組織學 或生物化學標準把病人分為皮質醇增多症或正常皮質醇分泌兩組。繪 製ROC曲線來找出截取值以及研究其表現特徵。量度病人的 24 小時尿 液游離皮質醇; 深夜唾液皮質醇和皮質素; 隔夜 $1 \mathrm{mg}$ dexamethasone 抑制血液皮質醇、唾液皮質醇和唾液皮質素。通過LC-MS / MS 測定 唾液和尿液樣本。

結果：本研究包含皮質醇增多症 21 例，正常皮質醇分泌 78 例 以 $13.50 \mathrm{nmol} / \mathrm{L}$ 皮質素為診斷標準, 深夜唾液皮質素的敏感性為 $94.7 \%$, 特異性 $87.2 \%$ 。前一晚服食 $1 \mathrm{mg}$ dexamethasone後, 以 $0.85 \mathrm{n} \mathrm{mol} / \mathrm{L}$ 唾液皮質醇為診斷標準的敏感性為 $76.2 \%$, 特異性 $96.2 \%$; 以 $7.45 \mathrm{nmol} / \mathrm{L}$ 唾液皮質素為診斷標準的敏感性為 $85.7 \%$ ， 特異性 $94.9 \%$; 以 $3.25 \mathrm{nmol} / \mathrm{L}$ 唾液皮質素為診斷標準的敏感性為 95.2\%，特異性79.5\%。許多唾液皮質醇樣本低於LC-MS / MS 的檢 測限。與唾液皮質醇相比, 唾液皮質素與血清皮質醇總量有較佳相關 性, dexamethasone抑制後的診斷性能較好。

結論：深夜唾液皮質素和隔夜 $1 \mathrm{mg}$ dexamethasone抑制唾液皮質素在 偵測皮質醇增多症中具診斷價值。

\section{Investigations performed}

Detailed oral and written instructions were given to all subjects by an endocrine specialist nurse. For the collection of saliva sample, subjects were instructed to refrain from smoking, brushing teeth, and eating or drinking anything but water for at least 30 minutes before collection. Saliva samples were collected using a cotton swab in Salivette tubes (Sarstedt, Nümbrecht, Germany). Salivettes were kept at $4^{\circ} \mathrm{C}$ in a home refrigerator and sent to the laboratory within 24 hours.

According to the pre-specified protocol, on day 1, a 24-hour urine sample was collected for UFC measurement. On day 2, a 0900h saliva sample was collected at the Endocrine Centre, under nurse supervision. The patient was then instructed to collect a late-night (between 2300h and 2400h) saliva sample that evening, after which he/she was to take dexamethasone $1 \mathrm{mg}$ orally. On day 3 , subjects returned to the Endocrine Centre for a simultaneous blood and saliva sample at 0900h. The blood sample was sent for serum cortisol assay. Saliva samples were assayed for both cortisol and cortisone.

\section{Laboratory assays}

Serum cortisol was measured by competitive 
chemiluminescent microparticle immunoassay using the Abbott ARCHITECT i2000SR system (Abbott Diagnostics, Illinois, US). The coefficient of variation of the assay for serum cortisol was $4.0 \%-6.2 \%$ at low levels and $3.3 \%-4.3 \%$ at high levels. Salivary cortisol and salivary cortisone were measured by LC-MS/MS using the Waters Xevo TQ MS system (Waters Corporation, Milford [MA], US). Cortisol and cortisone were extracted from saliva using the organic solvent methyl tert-butyl ether after addition of a deuterium-labelled internal standard mixture of cortisol-d4 and cortisone-d8 (CDN isotopes). The organic supernatant was dried under nitrogen at a temperature below $45^{\circ} \mathrm{C}$ and dissolved in the initial mobile phase for LC-MS/MS analysis. The steroid analytes were separated from the matrix background in a reversed-phase chromatography that employed a sub-2 $\mu \mathrm{m}$ analytical column (ACQUITY UPLC HSS T3 Column, 2.1 x $100 \mathrm{~mm}, 1.8 \mathrm{~mm}$; Waters Corporation, Milford [MA], US) and a 6-minute elution method consisting of a gradient mixture of $0.1 \%$ glacial acetic acid, $0.2 \mathrm{mM}$ ammonium acetate in water and methanol. Negative electrospray mode was used for analyte ionisation. The charged acetate adducts were monitored by multiple reaction monitoring mode with two stable mass transitions for cortisol $(421>331 ; 421>297)$ and cortisone $(419>329$; $419>301)$ and one multiple reaction monitoring for each of the corresponding deuterated internal standards (cortisol-d4: 425>335; cortisone-d8: $427>337$ ). Quantitative measurement was derived using the linear least squares regression method with origin excluded and $1 / x$ weighting for better accuracy at a low concentration level. The coefficient of variation of the assay for salivary cortisol and cortisone was $5 \%-7 \%$ and $7 \%-10 \%$, respectively across the analyte reporting ranges up to $250 \mathrm{nmol} / \mathrm{L}$. The lower limit of detection was $0.5 \mathrm{nmol} / \mathrm{L}$ for both salivary cortisol and cortisone. Urinary cortisol was also measured by LC-MS/MS. Adrenocorticotropic hormone $(\mathrm{ACTH})$ was measured by Immulite 2000 XPi (Siemens Healthcare GmbH, Erlangen, Germany) chemiluminescent immunometric assay. The upper reference limit of ACTH was $10.2 \mathrm{pmol} / \mathrm{L}$.

\section{Definition of hypercortisolism}

Subjects were classified as having hypercortisolism if either the biochemical or the histological criterion was fulfilled. The biochemical criterion was defined as having an abnormal value in at least two of the following three tests: (1) $\operatorname{SerF}_{\text {Dex }}>138 \mathrm{nmol} / \mathrm{L}$, or $>50 \mathrm{nmol} / \mathrm{L}$ in the context of adrenal incidentaloma ${ }^{15}$; (2) UFC >157 nmol/day; and (3) $\mathrm{SalF}_{\mathrm{LN}} \geq 3 \mathrm{nmol} / \mathrm{L}$. The categorisation of hypercortisolism was made without knowledge (ie blinded) of the three outcome parameters being evaluated for diagnostic accuracy, namely $\mathrm{SalE}_{\mathrm{LN}}$, post-overnight dexamethasone suppression salivary cortisol $\left(\operatorname{SalF}_{\mathrm{Dex}}\right)$, and $\mathrm{SalE}_{\mathrm{Dex}}$. The reference range for UFC in our laboratory, established locally from the 2.5th to 97.5th percentile of 112 healthy adults, was $22-157 \mathrm{nmol} /$ day. The reference level for $\mathrm{SalF}_{\mathrm{LN}}$ in our laboratory, derived from the 97.5th percentile of 61 normal individuals, was $<3 \mathrm{nmol} / \mathrm{L}$. The histological criterion was defined as histological proof and postoperative improvement in biochemical and clinical parameters. Subjects not fulfilling either of these criteria were classified as having eucortisolism.

\section{Statistical analyses}

For calculation purposes, results below the detection limit of the assay were set to the lowest detection value. Continuous data were expressed as mean \pm standard deviation if parametric, and median (range) if non-parametric. Chi squared test was used to detect any difference between categorical data. Unpaired $t$ test was used to compare continuous variables, and Mann-Whitney test was used for nonparametric data. A P value of $<0.05$ was considered statistically significant. Correlation between serum and salivary values were performed using Pearson correlation coefficients.

For estimation of the optimal diagnostic cut-off value, receiver operating characteristic (ROC) curves were drawn using data from the subjects classified as hypercortisolism or eucortisolism. The optimal cut-off was chosen where the Youden's index (sensitivity + specificity -1 ) was maximal. The test performance characteristics were calculated to assess their utility. The quality of diagnostic tests was expressed as the area under ROC curve (AUC). For sample size requirement estimation, for an estimated AUC of 0.8 , a minimum of nine positive cases was required. ${ }^{16}$ Statistical analysis was performed using the Statistical Package for Social Science (Windows version 20.0; IBM Corp, Armonk [NY], US).

\section{Results}

A total of 115 subjects were referred to our Endocrine Clinic for assessment of hypercortisolism during the study period. Of them, 14 subjects with a history of transsphenoidal surgery or adrenalectomy who had been referred for postoperative assessment of endocrine function were excluded. One patient with ongoing investigations and pending re-evaluation and another with end-stage renal failure were also excluded. No patient was taking exogenous steroids. All subjects had normal renal and liver function tests.

A total of 115 sets of biochemical investigations were performed in 99 subjects (40 males, 59 females; mean age, $55.3 \pm 14.3$ years; range, $19-81$ years) The primary indications for testing were adrenal incidentaloma in 52 subjects, suspected secondary hypertension or diabetes mellitus in 25, Cushingoid features in 21, and pituitary mass in one. Eleven 
subjects had two or more sets of investigations performed (two patients had 4 sets, one patient had 3 sets, and eight patients had 2 sets). For these subjects, only the data set with the highest SerF ${ }_{\text {Dex }}$ was chosen for analysis. In two subjects, the volume of the late-night salivary sample was inadequate for measurement.

In this study, 21 subjects were found to have hypercortisolism according to the above criteria-20 subjects met the biochemical criterion; eight subjects met the histological criterion, including one whose set of tests did not fulfil the biochemical criterion $\left(\operatorname{SerF}_{\text {Dex }} 135 \mathrm{nmol} / \mathrm{L}\right.$; normal UFC and SalF ${ }_{\mathrm{LN}}, \mathrm{ACTH}$ $1.1 \mathrm{pmol} / \mathrm{L}$ ) and who underwent surgery because of an adrenal adenoma that enlarged from $1.6 \mathrm{~cm}$ to $2.5 \mathrm{~cm}$ over 2 years, postoperative spot cortisol was $<28 \mathrm{nmol} / \mathrm{L}$ and hydrocortisone replacement was required for 6 months before axis recovery. Among the 21 subjects who had hypercortisolism, 7 had adrenal Cushing's, 4 pituitary Cushing's, 3 ectopic ACTH syndrome, 1 adrenocortical carcinoma, and 6 subclinical Cushing's. Of these subjects, 14 (67\%) had elevated UFC, 18 (86\%) had non-suppressed $\mathrm{SerF}_{\mathrm{Dex}}$, and 17 (81\%) had elevated $\mathrm{SalF}_{\mathrm{LN}}$. Among the eight subjects with histological proof $(6$ adrenalectomies, 1 transsphenoidal surgery, 1 enucleation of pancreatic neuroendocrine tumour), all had clinical and biochemical improvement after operation. Eucortisolism was diagnosed in 78 subjects according to the aforementioned criteria.

The baseline characteristics of the subjects are shown in Table 1 . There were no statistically significant differences between the hypercortisolism and the eucortisolism groups with respect to age, gender, and prevalence of obesity, diabetes mellitus, or hypertension. There was a statistically significantly higher prevalence of Cushingoid features and of proximal myopathy in the hypercortisolism group.

The biochemical test results are shown in Table 2. The hypercortisolism group had statistically significantly higher levels of SerF ${ }_{\text {Dex }}$ UFC, SalF ${ }_{\mathrm{LN}}$, $\operatorname{SalE}_{\mathrm{LN}}, \mathrm{SalF}_{\mathrm{Dex}}$, and $\mathrm{SalE}_{\mathrm{Dex}}$. No SalF $\mathrm{LN}_{\mathrm{LN}}$ sample in the hypercortisolism group and $17(21.8 \%)$ SalF $_{\mathrm{LN}}$ samples in the eucortisolism group had levels below the detection limit of $0.5 \mathrm{nmol} / \mathrm{L}$. No SalE $\mathrm{LN}_{\mathrm{L}}$ sample in the hypercortisolism group had levels below the detection limit of $0.5 \mathrm{nmol} / \mathrm{L}$. Four (19.0\%) SalF samples in the hypercortisolism group and 68

TABLE I. Baseline characteristics of study subjects*

\begin{tabular}{lccc}
\hline Baseline characteristic & Hypercortisolism $\mathbf{( n = 2 1 )}$ & Eucortisolism (n=78) & P value \\
\hline Age (years) & $58.9 \pm 14.2$ & $54.3 \pm 14.3$ & 0.320 \\
Male:female & $6: 15$ & $34: 44$ & \\
Clinical features & & & 0.488 \\
\hline Obesity & $9(42.9 \%)$ & $27(34.6 \%)$ & 0.255 \\
\hline Diabetes mellitus & $5(23.8 \%)$ & $29(37.2 \%)$ & 0.292 \\
\hline Hypertension & $17(81.0 \%)$ & $54(69.2 \%)$ & 0.001 \\
\hline Cushingoid features & $10(47.6 \%)$ & $11(14.1 \%)$ & 0.005 \\
\hline Proximal myopathy & $4(19.0 \%)$ & $2(2.6 \%)$ & \\
\hline
\end{tabular}

* Data are shown as mean \pm standard deviation, No. of patients, or No. (\%) of patients, unless otherwise stated

TABLE 2. Biochemical test results of study subjects

\begin{tabular}{lccc}
\hline & \multicolumn{2}{c}{ Median (range) } & \multicolumn{2}{c}{ P value } \\
\cline { 2 - 3 } & Hypercortisolism (n=21*) & Eucortisolism (n=78) & \\
\hline Post-overnight dexamethasone suppression serum cortisol (nmol/L) & $206.0(30-1081)$ & $28.0(6.0-200)$ & $<0.001$ \\
24-Hour urinary free cortisol (nmol/d) & $219.0(80.0-7570)$ & $88.5(2.0-248.0)$ & $<0.001$ \\
Late-night salivary cortisol (nmol/L) & $5.4(1.7-41.0)$ & $1.0(0.5-12.0) \dagger$ & $<0.001$ \\
Late-night salivary cortisone (nmol/L) & $30.0(11.0-148.0)$ & $7.1(0.9-49.0)$ & $<0.001$ \\
Post-overnight dexamethasone suppression salivary cortisol (nmol/L) & $2.0(0.5-72) \ddagger$ & $0.5(0.5-3.4) \S$ & $<0.001$ \\
Post-overnight dexamethasone suppression salivary cortisone (nmol/L) & $17.0(2.0-266.0)$ & $2.0(0.5-15.0) \|$ & $<0.001$ \\
\hline
\end{tabular}

* 2 Sets of data which had inadequate late-night salivary samples for measurement were excluded

$\dagger 21.8 \%$ of subjects had levels below the detection limit $(0.5 \mathrm{nmol} / \mathrm{L})$

$\ddagger 19.0 \%$ of subjects had levels below the detection limit $(0.5 \mathrm{nmol} / \mathrm{L})$

$\S 87.2 \%$ of subjects had levels below the detection limit $(0.5 \mathrm{nmol} / \mathrm{L})$

|| $1.3 \%$ of subjects had levels below the detection limit $(0.5 \mathrm{nmol} / \mathrm{L})$ 
(87.2\%) SalF $_{\text {Dex }}$ samples in the eucortisolism group had a level below the detection limit of $0.5 \mathrm{nmol} / \mathrm{L}$. One (1.3\%) SalE ${ }_{\text {Dex }}$ sample in the eucortisolism group had a level below the detection limit of $0.5 \mathrm{nmol} / \mathrm{L}$.

The ROC analysis (Fig 1) and Table 3 reveal that the optimal cut-off for $\mathrm{SalE}_{\mathrm{LN}}$ was $13.50 \mathrm{nmol} / \mathrm{L}$. Setting the specificity at a level of $95 \%$, the cut-off for $\mathrm{SalE}_{\mathrm{LN}}$ would be $20.50 \mathrm{nmol} / \mathrm{L}$.

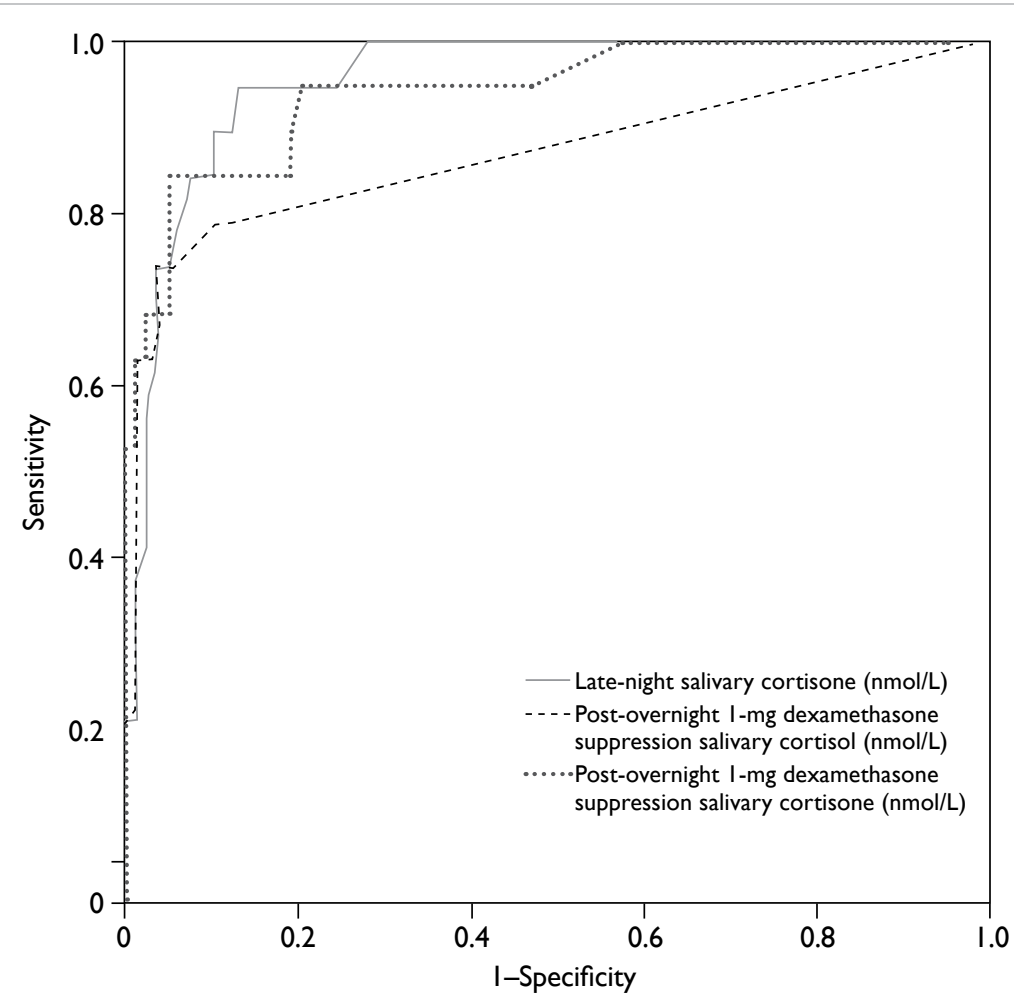

FIG I. Receiver operating characteristic curves for late-night salivary cortisone, and post-overnight I-mg dexamethasone suppression salivary cortisol and cortisone

Diagonal segments are produced by ties
After overnight 1-mg dexamethasone suppression, the optimal cut-off for SalF ${ }_{\text {Dex }}$ was 0.85 nmol/L (Table 3). Nonetheless, these values should be interpreted with caution, since many SalF $_{\text {Dex }}$ values in both the eucortisolism (87.2\%) and hypercortisolism (19.0\%) groups were below the detection limit of the LC-MS/MS assay and were consequently presumed to be equivalent to the lowest detection limit of $0.5 \mathrm{nmol} / \mathrm{L}$.

After 1-mg overnight dexamethasone suppression, the optimal cut-off for $\mathrm{SalE}_{\mathrm{Dex}}$ was $7.45 \mathrm{nmol} / \mathrm{L}$. Setting the sensitivity at a level of $95 \%$, the cut-off for $\mathrm{SalE}_{\text {Dex }}$ would be $3.25 \mathrm{nmol} / \mathrm{L}$ (Table $3)$.

The correlation between $0900 \mathrm{~h}$ serum cortisol and salivary cortisol was $0.81 \quad(\mathrm{P}<0.01)$; and that between $0900 \mathrm{~h}$ serum cortisol and salivary cortisone was $0.88(\mathrm{P}<0.01)$. The correlation between $\operatorname{SerF}_{\text {Dex }}$ and $\mathrm{SalF}_{\text {Dex }}$ was $0.90(\mathrm{P}<0.01)$; and that between SerF $_{\text {Dex }}$ and $\mathrm{SalE}_{\text {Dex }}$ was 0.94 $(\mathrm{P}<0.01)$ [Fig 2].

\section{Discussion}

All investigators who study Cushing's syndrome are confronted with the conundrum of accurately diagnosing or excluding the condition with no gold standard test. ${ }^{1}$ In our study, in addition to the histological criterion, we considered it appropriate to include a set of biochemical criteria in which subjects with two positive results among the three commonly used tests-namely the $\operatorname{SerF}_{\text {Dex }}$, the UFC, and the $\mathrm{SalF}_{\mathrm{LN}}$-were considered to have hypercortisolism. This is in agreement with the Endocrine Society Clinical Practice Guideline ${ }^{17}$ that recommends performing one or two other tests if one of these is abnormal; and if results from two different tests are concordant, to proceed with investigations to establish the cause of Cushing's syndrome. One wellrecognised contentious point in the interpretation of the $\operatorname{SerF}_{\text {Dex }}$ is the optimal cut-off: $<140 \mathrm{nmol} / \mathrm{L}$ is a widely cited normal response, but can lead to

TABLE 3. Performance characteristics of late-night salivary cortisone, and post-overnight I-mg dexamethasone suppression salivary cortisol and cortisone

\begin{tabular}{|c|c|c|c|c|c|c|}
\hline & \multirow[t]{2}{*}{ AUC (mean \pm SD) } & \multirow[t]{2}{*}{ Cut-off (nmol/L) } & \multirow{2}{*}{$\begin{array}{l}\text { Sensitivity } \\
(\%)\end{array}$} & \multirow{2}{*}{$\begin{array}{l}\text { Specificity } \\
(\%)\end{array}$} & \multicolumn{2}{|c|}{ Likelihood ratio } \\
\hline & & & & & + & - \\
\hline Late-night salivary cortisone & $0.954 \pm 0.020$ & $\begin{array}{c}13.50 \text { (optimalt) } \\
20.50 \text { (at specificity level of } 95 \% \text { ) }\end{array}$ & $\begin{array}{l}94.7 \\
73.7\end{array}$ & $\begin{array}{l}87.2 \\
95\end{array}$ & $\begin{array}{l}7.40 \\
73.7\end{array}$ & $\begin{array}{l}0.06 \\
0.28\end{array}$ \\
\hline $\begin{array}{l}\text { Post-overnight dexamethasone } \\
\text { suppression salivary cortisol* }\end{array}$ & $0.881 \pm 0.054$ & 0.85 (optimal†) & 76.2 & 96.2 & 20.05 & 0.25 \\
\hline $\begin{array}{l}\text { Post-overnight dexamethasone } \\
\text { suppression salivary cortisone }\end{array}$ & $0.947 \pm 0.028$ & $\begin{array}{c}7.45 \text { (optimal†) } \\
3.25 \text { (at sensitivity level of } 95 \% \text { ) }\end{array}$ & $\begin{array}{l}85.7 \\
95.2\end{array}$ & $\begin{array}{l}94.9 \\
79.5\end{array}$ & $\begin{array}{r}16.80 \\
4.64\end{array}$ & $\begin{array}{l}0.15 \\
0.06\end{array}$ \\
\hline
\end{tabular}

Abbreviations: $A \cup C=$ area under the curve; LC-MS/MS = liquid chromatography-tandem mass spectrometry; SD = standard deviation

* Data to be interpreted with caution since many values are below the detection limit of the LC-MS/MS assay and taken to be equivalent to the lowest detection limit of $0.5 \mathrm{nmol} / \mathrm{L}$

† The optimal cut-off is chosen where the Youden's index, ie "sensitivity + specificity-I", is maximal 

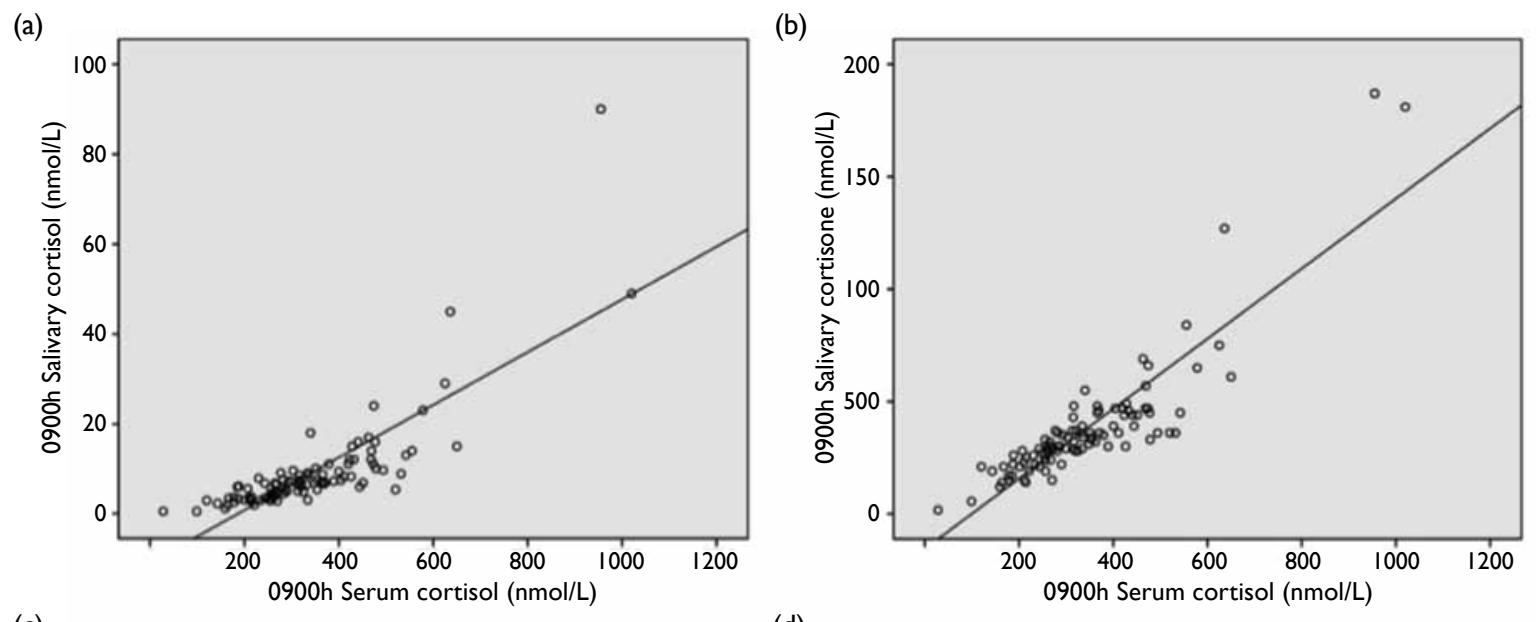

(c)
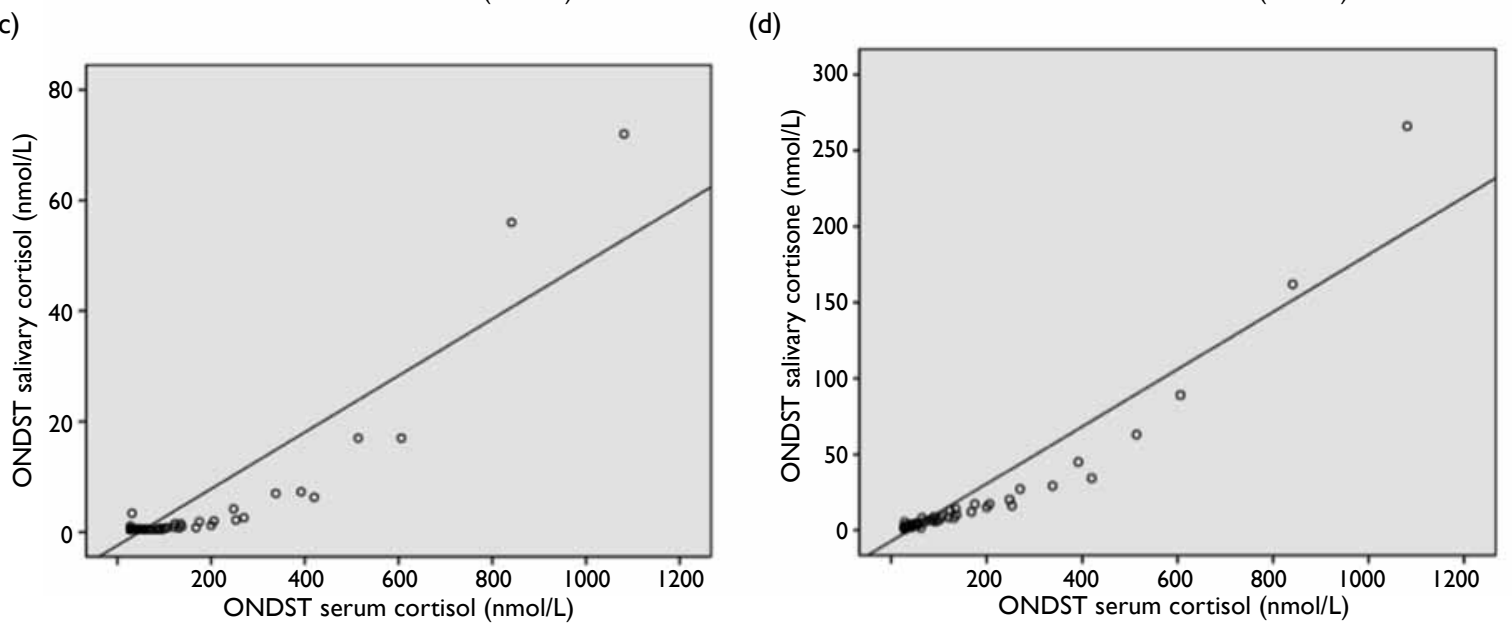

FIG 2. Correlation plots between $0900 \mathrm{~h}$ serum cortisol versus (a) salivary cortisol and (b) salivary cortisone; and between post-dexamethasone serum cortisol versus (c) salivary cortisol and (d) salivary cortisone
(a) Pearson correlation coefficient $=0.81 \quad(P<0.01)$
(b) Pearson correlation coefficient $=0.88(\mathrm{P}<0.0 \mathrm{I})$
(c) Pearson correlation coefficient $=0.90(P<0.01)$
(d) Pearson correlation coefficient $=0.94(\mathrm{P}<0.01)$
Abbreviation: ONDST = overnight dexamethasone suppression test

false-negative results in up to $15 \%$ of subjects with Cushing's syndrome. ${ }^{18,19}$ The more stringent cut-off of $<50 \mathrm{nmol} / \mathrm{L}$ sacrifices specificity for sensitivity. ${ }^{20,21}$ In this study, we adopted a double cut-off as proposed by the European Society of Endocrinology Clinical Practice Guideline in collaboration with the European Network for the Study of Adrenal Tumors ${ }^{15}$; the rationale being that a more sensitive cut-off should be employed in those with a higher pretest probability of Cushing's syndrome, such as the presence of an adrenal adenoma on imaging studies. ${ }^{22} \mathrm{~A}$ more specific cut-off can be employed in general to avoid overdiagnosis.

The loss of circadian rhythm with absence of a late-night cortisol nadir is a well-established feature of Cushing's syndrome. Midnight serum cortisol is, however, difficult to obtain. When $\operatorname{SalF}_{\mathrm{LN}}$ was shown to correlate well with serum cortisol levels, with sensitivity of 92\%-100\% and specificity of 93\%$100 \%$ for the diagnosis of Cushing's syndrome, ${ }^{17}$ it rapidly became one of the most popular tests in investigating endogenous hypercortisolism. In view of the theoretical advantages of salivary cortisone, we also attempted to explore the performance characteristics of $\mathrm{SalE}_{\mathrm{LN}}$. Our data showed that it had a good sensitivity of $94.7 \%$ and a specificity of $87.2 \%$ at the cut-off of $13.50 \mathrm{nmol} / \mathrm{L}$, as measured by LC-MS/MS.

We could not compare the utility of $\operatorname{SalF}_{\mathrm{LN}}$ with cortisone in this study, since $\mathrm{SalF}_{\mathrm{LN}}$ was one of the criteria applied to define Cushing's syndrome. Simultaneous measurement of salivary cortisol and 
salivary cortisone can nonetheless alert clinicians to certain caveats encountered when measuring salivary cortisol alone. When the salivary cortisolto-cortisone ratio is exceptionally high, direct contamination of the oral sample by topical or oral hydrocortisone must be excluded. Ingestion of glycyrrhetinic acid (eg in licorice, carbenoxolone), which competitively inhibits $11 \beta-$ HSD2, or rare cases of genetic $11 \beta$-HSD2 defect, can also lead to the same anomaly.

A number of other investigators have explored the utility of $\mathrm{SalF}_{\text {Dex }}$ in the diagnosis of Cushing's syndrome. Apart from its convenience, salivary values are not affected by conditions that affect corticosteroid-binding globulin (CBG) or albumin levels, such as acute and chronic illness, pregnancy or oestrogen treatment, or genetic variants of CBG. A sensitivity varying between $97 \%$ and $100 \%$ and a specificity between $77 \%$ and $100 \%$ have been variously reported, with cut-off level varying between $1.7 \mathrm{nmol} / \mathrm{L}$ and $2 \mathrm{nmol} / \mathrm{L} \cdot{ }^{6-9}$ In the current study, we found that the sensitivity of $\mathrm{SalF}_{\text {Dex }}$ was only $76.2 \%$ at the optimal cut-off of $0.85 \mathrm{nmol} / \mathrm{L}$. Although this discrepancy with other studies might be due to a number of factors, such as the means of defining normal ranges and the criteria for diagnosing Cushing's syndrome, one important factor that is evident from our data is the method used for assaying salivary cortisol: some used electrochemiluminescence assay, ${ }^{9}$ others used radioimmunoassay ${ }^{6-8}$; but we measured SalF $_{\text {Dex }}$ with LC-MS/MS. ${ }^{12}$ Unlike immunoassays, LC-MS/MS measurement of analytes is more specific, with less cross-reactivity among different cortisol precursors and metabolites. ${ }^{23}$ The concentration of SalF ${ }_{\text {Dex }}$ was very low: $19 \%$ of our patients with hypercortisolism and $87 \%$ of those with eucortisolism had SalF $_{\text {Dex }}$ below the detection limit of $0.5 \mathrm{nmol} / \mathrm{L}$, leading to uncertainty in establishing the cut-off, since all those with results of $<0.5 \mathrm{nmol} / \mathrm{L}$ could only be considered to have salivary cortisol level equal to $0.5 \mathrm{nmol} / \mathrm{L}$ in the analysis. Immunoassays, by measuring other cortisol precursors or metabolites in varying degrees in addition, could have bypassed this problem. Other studies have also reported that $\mathrm{SalF}_{\mathrm{LN}}$ has poorer diagnostic performance characteristics if measured by LC-MS/MS, in comparison with the less-specific immunoassays such as chemiluminescent assays or radioimmunoassays. ${ }^{24,25}$

Nevertheless, LC-MS/MS is analytically more superior and is expected to become the steroid assay of choice in the future. ${ }^{26}$ Values generated by studies using LC-MS/MS have greater inter-centre and long-term generalisability in view of the lack of assay-specific steroid cross-reactivity. Adoption of cut-offs generated by studies in which salivary cortisol was assayed using antibody-based methods into clinical practice is known to be problematic. ${ }^{27}$
Individual centres are often advised to generate their own references and cut-offs although this is often not feasible. In a meta-analysis on the use of SalF $_{\mathrm{LN}}$ for investigation of Cushing's syndrome, ${ }^{25}$ the recommended cut-offs varied widely, from 3.59 to $15.17 \mathrm{nmol} / \mathrm{L}$. To overcome the problem of lower performance characteristics due to low levels of salivary cortisol, instead of going for immunoassays, a better solution may be to measure salivary cortisone that is present in a much higher concentration than salivary cortisol. At a serum cortisol below $74 \mathrm{nmol} / \mathrm{L}$, Debono et $\mathrm{a}^{28}$ showed that salivary cortisol could become undetectable by LC-MS/MS, while salivary cortisone was always detected. Similarly, our data showed that after dexamethasone suppression, when the salivary cortisol became too low to be measured with LC-MS/MS in many subjects, salivary cortisone could still be measured in all but one subject in the eucortisolism group.

Between salivary cortisol and salivary cortisone, this study showed that salivary cortisone would be the preferred test because it is present at a higher concentration in the saliva; and at comparable specificity levels, SalE ${ }_{\text {Dex }}$ appears to have better accuracy (as reflected by the higher AUC of the ROC curves), sensitivity, and negative LR than SalF ${ }_{\text {Dex }}$.

Apart from the optimal cut-off, clinically it is often useful to have two cut-offs, one for ruling in a diagnosis (high specificity) and another one for excluding a diagnosis (high sensitivity), depending on clinicians' preference. If we arbitrarily define an acceptable and useful cut-off as having a 95\% level of either sensitivity or specificity, the two useful cutoffs for SalE ${ }_{\mathrm{LN}}$ as derived from our study were 13.50 and $20.50 \mathrm{nmol} / \mathrm{L}$, respectively; those for $\mathrm{SalE}_{\mathrm{Dex}}$ were $3.25 \mathrm{nmol} / \mathrm{L}$ and $7.45 \mathrm{nmol} / \mathrm{L}$, respectively.

Traditionally, in the algorithm for the workup for Cushing's syndrome, late-night levels (serum or salivary cortisol) have been used for screening (excluding Cushing's syndrome), whereas the postdexamethasone level (serum cortisol) has been used for diagnosis (ruling in Cushing's syndrome). When used as such, the cut-off of $13.50 \mathrm{nmol} / \mathrm{L}$ can be used for $\mathrm{SalE}_{\mathrm{LN}}$; whereas $7.45 \mathrm{nmol} / \mathrm{L}$ can be used for SalE ${ }_{\text {Dex }}$. For the time being, SalE ${ }_{\text {Dex }}$ data can supplement serum cortisol measurement as a confirmatory test when concordant, or alert the clinician to the potential pitfalls with serum cortisol (eg variations in CBG levels) when discordant. With more experience, $\mathrm{SalE}_{\mathrm{Dex}}$ may even ultimately replace the need to measure serum cortisol.

The strength of this study lies in the rigour with which a pre-specified protocol was adhered to. A high success rate of sample collection was achieved, with little missing data. Insufficient salivary volume collected in the Salivette tubes was the most common reason for unsuccessful salivary collection, because LC-MS/MS requires a larger 
saliva volume (100-250 $\mu \mathrm{L})$ than immunoassay $(40-50 \mu \mathrm{L}){ }^{29}$ Two thirds of our study subjects were referred either because of an adrenal incidentaloma or common clinical conditions such as diabetes mellitus and hypertension, and had no clinical features of Cushing's syndrome. This population was quite representative of cases referred to an endocrine centre for workup of Cushing's syndrome.

A notable limitation of this study is the small number of subjects with hypercortisolism. The cut-off for the $\operatorname{SerF}_{\text {Dex }}$ was adopted from the literature rather than from data derived from our own healthy volunteers. The Endocrine Society Clinical Practice Guideline ${ }^{17}$ recommended two separate measurements of $\mathrm{SalF}_{\mathrm{LN}}$ or UFC. Only one sample for each was collected in our study. Although we might have consequently missed some cases of episodic hypercortisolism, we assumed that if less than two out of the relatively sensitive tests were positive at the time of sampling, the subjects would likely be in a phase of normal cortisol secretion even if they had episodic Cushing's syndrome.

\section{Conclusions}

Our study showed that salivary cortisone can become the analyte of choice for investigating Cushing's syndrome in the era of LC-MS/MS. Our data suggest using $13.50 \mathrm{nmol} / \mathrm{L}$ for $\mathrm{SalE}_{\mathrm{LN}}$, and either $7.45 \mathrm{nmol} / \mathrm{L}$ (more specific) or $3.25 \mathrm{nmol} / \mathrm{L}$ (more sensitive) for SalE ${ }_{\text {Dex }}$, as cut-offs.

\section{Declaration}

All authors have disclosed no conflicts of interest.

\section{References}

1. Stewart PM. Is subclinical Cushing's syndrome an entity or a statistical fallout from diagnostic testing? Consensus surrounding the diagnosis is required before optimal treatment can be defined. J Clin Endocrinol Metab 2010;95:2618-20.

2. Ferraù F, Korbonits M. Metabolic comorbidities in Cushing's syndrome. Eur J Endocrinol 2015;173:M133-57.

3. Viardot A, Huber P, Puder JJ, Zulewski H, Keller U, Müller B. Reproducibility of nighttime salivary cortisol and its use in the diagnosis of hypercortisolism compared with urinary free cortisol and overnight dexamethasone suppression test. J Clin Endocrinol Metab 2005;90:5730-6.

4. Graham UM, Hunter SJ, McDonnell M, Mullan KR, Atkinson AB. A comparison of the use of urinary cortisol to creatinine ratios and nocturnal salivary cortisol in the evaluation of cyclicity in patients with Cushing's syndrome. J Clin Endocrinol Metab 2013;98:E72-6.

5. Vining RF, McGinley RA, Maksvytis JJ, Ho KY. Salivary cortisol: a better measure of adrenal cortical function than serum cortisol. Ann Clin Biochem 1983;20(Pt 6):329-35.

6. Barrou Z, Guiban D, Maroufi A, et al. Overnight dexamethasone suppression test: comparison of plasma and salivary cortisol measurement for the screening of Cushing's syndrome. Eur J Endocrinol 1996;134:93-6.
7. Cardoso EM, Arregger AL, Tumilasci OR, Contreras LN. Diagnostic value of salivary cortisol in Cushing's syndrome (CS). Clin Endocrinol (Oxf) 2009;70:516-21.

8. Castro M, Elias PC, Quidute AR, Halah FP, Moreira AC. Out-patient screening for Cushing's syndrome: the sensitivity of the combination of circadian rhythm and overnight dexamethasone suppression salivary cortisol tests. J Clin Endocrinol Metab 1999;84:878-82.

9. Deutschbein T, Broecker-Preuss M, Flitsch J, et al. Salivary cortisol as a diagnostic tool for Cushing's syndrome and adrenal insufficiency: improved screening by an automatic immunoassay. Eur J Endocrinol 2012;166:613-8.

10. Perogamvros I, Keevil BG, Ray DW, Trainer PJ. Salivary cortisone is a potential biomarker for serum free cortisol. J Clin Endocrinol Metab 2010;95:4951-8.

11. Wood P. Salivary steroid assays-research or routine? Ann Clin Biochem 2009;46(Pt 3):183-96.

12. Antonelli G, Ceccato F, Artusi C, Marinova M, Plebani M. Salivary cortisol and cortisone by LC-MS/MS: validation, reference intervals and diagnostic accuracy in Cushing's syndrome. Clin Chim Acta 2015;451(Pt B):247-51.

13. Smith RE, Maguire JA, Stein-Oakley AN, et al. Localization of 11 beta-hydroxysteroid dehydrogenase type II in human epithelial tissues. J Clin Endocrinol Metab 1996;81:3244-8.

14. Perogamvros I, Owen LJ, Newell-Price J, Ray DW, Trainer PJ, Keevil BG. Simultaneous measurement of cortisol and cortisone in human saliva using liquid chromatographytandem mass spectrometry: application in basal and stimulated conditions. J Chromatogr B Analyt Technol Biomed Life Sci 2009;877:3771-5.

15. Fassnacht M, Arlt W, Bancos I, et al. Management of adrenal incidentalomas: European Society of Endocrinology Clinical Practice Guideline in collaboration with the European Network for the Study of Adrenal Tumors. Eur J Endocrinol 2016;175:G1-G34.

16. Hanley JA, McNeil BJ. The meaning and use of the area under a receiver operating characteristic (ROC) curve. Radiology 1982;143:29-36.

17. Nieman LK, Biller BM, Findling JW, et al. The diagnosis of Cushing's syndrome: an Endocrine Society Clinical Practice Guideline. J Clin Endocrinol Metab 2008;93:152640.

18. FindlingJW, RaffH, Aron DC. The low-dose dexamethasone suppression test: a reevaluation in patients with Cushing's syndrome. J Clin Endocrinol Metab 2004;89:1222-6.

19. Görges R, Knappe G, Gerl H, Ventz M, Stahl F. Diagnosis of Cushing's syndrome: re-evaluation of midnight plasma cortisol vs urinary free cortisol and low-dose dexamethasone suppression test in a large patient group. J Endocrinol Invest 1999;22:241-9.

20. Ceccato F, Barbot M, Zilio M, et al. Screening tests for Cushing's syndrome: urinary free cortisol role measured by LC-MS/MS. J Clin Endocrinol Metab 2015;100:3856-61.

21. Nieman LK. Cushing's syndrome: update on signs, symptoms and biochemical screening. Eur J Endocrinol 2015;173:M33-8.

22. Lopez D, Luque-Fernandez MA, Steele A, Adler GK, Turchin A, Vaidya A. "Nonfunctional" adrenal tumors and the risk for incident diabetes and cardiovascular outcomes: a cohort study. Ann Intern Med 2016;165:533-42.

23. Raff $H$, Auchus RJ, Findling JW, Nieman LK. Urine free cortisol in the diagnosis of Cushing's syndrome: is it worth doing and, if so, how? J Clin Endocrinol Metab 
2015;100:395-7.

24. Erickson D, Singh RJ, Sathananthan A, Vella A, Bryant SC. Late-night salivary cortisol for diagnosis of Cushing's syndrome by liquid chromatography/tandem mass spectrometry assay. Clin Endocrinol (Oxf) 2012;76:467-72.

25. Carroll T, Raff H, Findling JW. Late-night salivary cortisol for the diagnosis of Cushing syndrome: a meta-analysis. Endocr Pract 2009;15:335-42.

26. Handelsman DJ, Wartofsky L. Requirement for mass spectrometry sex steroid assays in the Journal of Clinical Endocrinology and Metabolism. J Clin Endocrinol Metab
2013;98:3971-3

27. Beko G, Varga I, Glaz E, et al. Cutoff values of midnight salivary cortisol for the diagnosis of overt hypercortisolism are highly influenced by methods. Clin Chim Acta 2010;411:364-7.

28. Debono M, Harrison RF, Whitaker MJ, et al. Salivary cortisone reflects cortisol exposure under physiological conditions and after hydrocortisone. J Clin Endocrinol Metab 2016;101:1469-77.

29. Raff H. Cushing's syndrome: diagnosis and surveillance using salivary cortisol. Pituitary 2012;15:64-70. 